\title{
Choose MyPlate: Drink Water Instead of Sugary Drinks ${ }^{1}$
}

\author{
Jeanine Beatty, Karla Shelnutt, and Gail Kauwell ${ }^{2}$
}

Did you know that water makes up more than half your body weight? Every cell in your body needs water to function correctly. That's why it's important to stay hydrated. To stay hydrated you need to replace the water you lose through breathing, sweating, and urinating. Although all beverages help with hydration by providing some water, certain beverages are better choices than others. The information in this publication can help you learn why water is the best beverage choice.

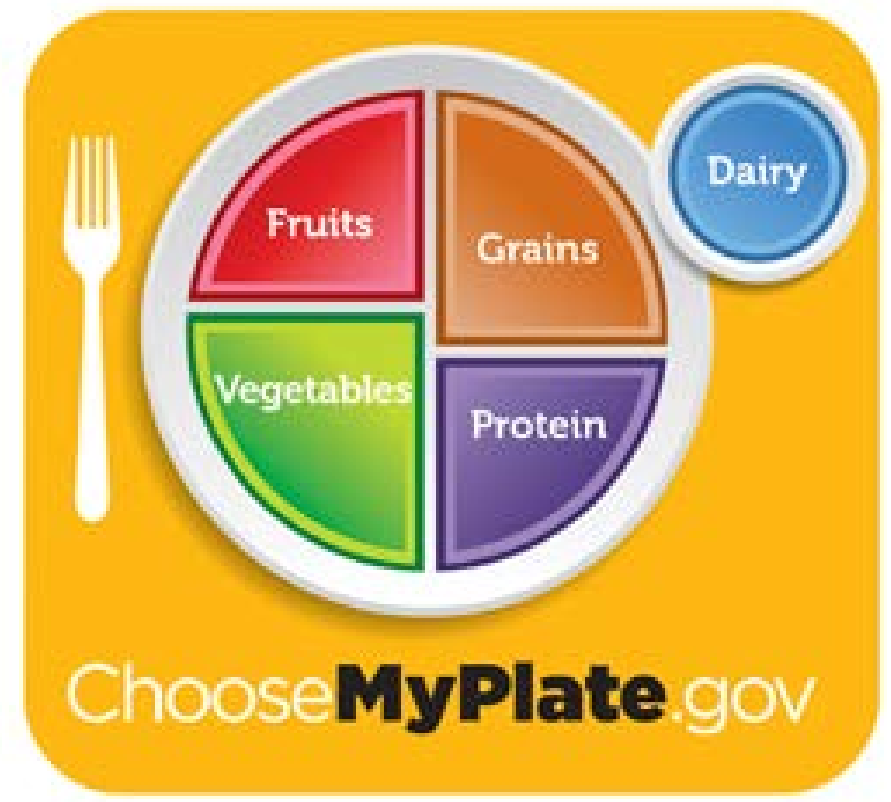

Figure 1. USDA's MyPlate recommends that people choose water instead of sugary, sweetened beverages.

Credits: http://www.choosemyplate.gov/

\section{Why Water?}

Water doesn't have calories or sugar, but drinks such as soda, fruit drinks, and sports drinks all contain added sugars. This means that sugar has been added to them, usually to make them taste sweeter. Sugary drinks are high in calories and low in nutrients. The average 20 -ounce bottle of soda contains 65 grams of sugar - that's 16 teaspoons! Can you imagine scooping 16 teaspoons of sugar into your morning cup of coffee? That same bottle of soda also contains 260 calories, all from sugar. Consuming too many calories can cause you to gain weight, leading to serious health problems like heart disease and diabetes. Consuming a lot of sugar can also affect your teeth, increasing your risk of developing painful and costly cavities. Clearly, water is the ideal choice to meet your body's fluid needs.

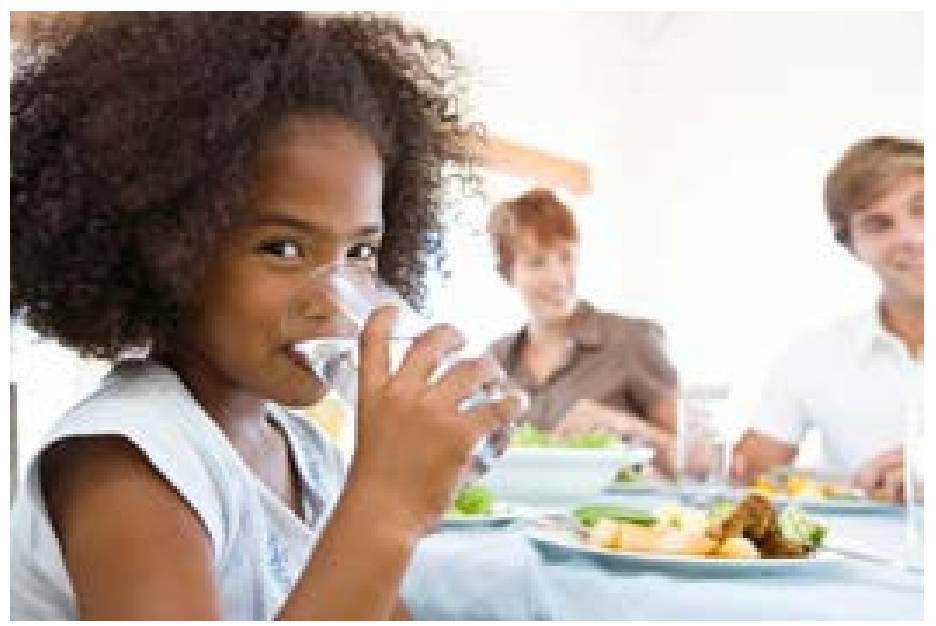

Figure 2. Water is the ideal choice for hydrating your body because it has no added sugar or calories.

Credits: Jupiterimages

1. This document is FCS80025, one of a series of the Department of Family, Youth, and Community Sciences, Florida Cooperative Extension Service, Institute of Food and Agricultural Sciences, University of Florida. First published April 2013. Please visit the EDIS website at http://edis.ifas.ufl.edu.

2. Jeanine Beatty, dietetic intern, Master of Science-Dietetic Internship Program, Food Science and Human Nutrition Department; Karla P. Shelnutt, PhD, RD, assistant professor, Department of Family, Youth and Community Sciences; Gail P.A. Kauwell, PhD, RD, professor, Food Science and Human Nutrition Department; Florida Cooperative Extension Service, Institute of Food and Agricultural Sciences, University of Florida, Gainesville, FL 32611. 


\section{What's in Your Drink?}

Choosing water over sugary drinks can make a big difference to your overall health and well-being. The following chart compares the amount of calories and sugar found in various drinks and water.

Table 1. Amount of sugar and calories in various beverages.

\begin{tabular}{|l|c|c|}
\hline \multicolumn{1}{|c|}{ Beverage (12 fluid ounces) } & Sugar (tsp) & Calories \\
\hline Water & 0 & 0 \\
\hline Sports Drink & 5 & 80 \\
\hline Cola & 8 & 128 \\
\hline Sweet Tea & 8 & 128 \\
\hline Energy Drink & 9 & 144 \\
\hline Fruit Drink & 10 & 160 \\
\hline
\end{tabular}

\section{Sugar, Sugar, Sugar}

Added sugars can go by many different names, but they all provide extra calories and can have the same bad effects on your health. Other names for added sugars include the following:

- high fructose corn syrup

- rice, malt, or cane syrup

- cane sugar or cane juice

- raw, brown, powdered, or invert sugar

- glucose, sucrose, maltose, dextrose, or lactose

- honey or molasses

- fruit juice concentrate

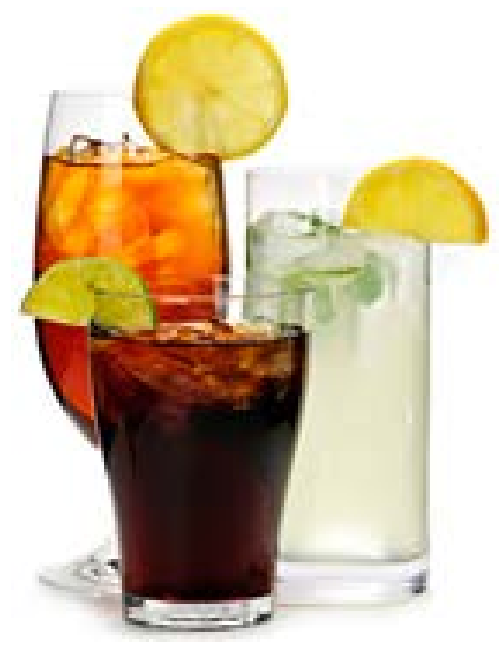

Figure 3. Sugar can go by many names in drinks — high fructose corn syrup, cane syrup, raw sugar, glucose or sucrose, honey or molasses, or fruit juice concentrate, to name a few. Always read the food label to see how much sugar has been added to a drink.

Credits: Hemera
Use the Nutrition Facts Panel to find out how much sugar is in a single serving of different beverages and choose the one lowest in sugar! Although the panel is helpful for finding total sugar, it does not differentiate between natural sugar and added sugars. For example, sugar would be listed on the Nutrition Facts Panel for both 100\% orange juice and an orange drink, but only the orange drink will have sugar added to it. You can learn more about the Nutrition Facts Panel by reading the EDIS publication FY1127/FCS8883 Healthy Eating: Understanding the Nutrition Facts Label (https://edis.ifas.ufl.edu/fy1127).

\section{$100 \%$ Fruit Juice, Milk, and Diet Drinks}

Although 100\% fruit juice has no added sugars, it lacks the dietary fiber found in fresh fruits and contains calories from natural sugars. It can still be part of a healthful diet when consumed in small amounts. Fruit drinks, on the other hand, contain added sugars and typically do not offer the same nutritional value as $100 \%$ juice products.

Like 100\% fruit juice, milk contains natural sugar, but it is still a great, nutrient-rich beverage choice, especially if low-fat or fat-free milk is consumed. Many children prefer flavored milks, which can also play a part in meeting daily needs.

Even though diet drinks are low in calories, they have no nutritional value. Diet drinks are an alternative to sugary drinks, but water is still the best choice.

\section{Making the Switch}

Now is time to start making the change to drinking primarily water, if you aren't already doing so. The following tips can help you stay hydrated and consume fewer calories and less sugar from beverages:

- Start the day with a glass of water!

- Always choose water over sugary drinks. Add fresh fruit or vegetable slices such as lemon, pineapple, or cucumber to add a naturally sweet flavor.

- If you miss the bubbly part of soda, try seltzer or sparkling water instead.

- If you choose to continue to drink sugary drinks, do so in moderation and not on a daily basis.

- Dilute sports drinks with water. 
- Choose $100 \%$ fruit or vegetable juices in small amounts over fruit drinks. It is better to eat your fruits and vegetables than to drink them!

- Make nutritious, fat-free or low-fat milk a regular beverage choice.

- Decaffeinated or herbal tea is a low-calorie option that also contains many healthful antioxidants.

- Avoid making sugary drinks available in your home. This is especially true for soda because you may be tempted to finish the whole can or bottle before it goes flat.

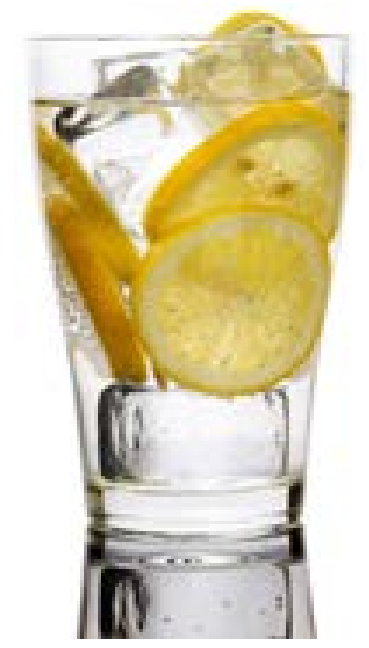

Figure 4. Adding lemon, lime, or cucumber to your water can give it some flavor and you may not even miss the extra sugar of a sweetened drink!

Credits: Hemera

\section{Summary}

The regular consumption of sugary drinks has greatly increased over the past few decades. Most adults consume about 400 calories per day as beverages, and regular soda is the number one drink. The added sugars and calories in sugary drinks can really add up - so rethink what you drink! Use one or more of the tips provided to drink more water and get on the right track to living a healthier life.

\section{References and Resources}

New York City Department of Health and Mental Hygiene. (2012). Sugar-sweetened beverages - the facts. Retrieved from http://www.nyc.gov/html/doh/downloads/pdf/cdp/ cdp-pop-the-fact.pdf

U.S. Department of Agriculture and U.S. Department of Health and Human Services. (2010). Dietary guidelines for Americans, 2010. 7th Edition, Washington, DC: U.S. Government Printing Office.
U.S. Department of Agriculture. (2011). National nutrient database for standard reference, 2011. Retrieved from http://ndb.nal.usda.gov/ 